\title{
Effect of Temperature on Methylene Blue Decolorization in Aqueous Medium in Electrical Discharge Plasma Reactor
}

\author{
Luís O. de B. Benetoli, ${ }^{*}, a$ Bruno M. Cadorin, ${ }^{a}$ Cícero da S. Postiglione, ${ }^{b}$ \\ Ivan G. de Souza ${ }^{a}$ and Nito A. Debacher*,a \\ ${ }^{a}$ INCT-Catalises, Departamento de Química, CFM, 88040-900 and ${ }^{b} I N E P$, Departamento de Engenharia Elétrica, \\ CTC, 88040-970, Universidade Federal de Santa Catarina, Florianópolis-SC, Brazil
}

\begin{abstract}
Este estudo investigou o efeito da temperatura da solução sobre a descoloração do azul de metileno em um reator de plasma de descarga elétrica do tipo ponta-plano. Os resultados mostraram um aumento da porcentagem inicial de descoloração do corante com o aumento da temperatura da solução de 4 para $28^{\circ} \mathrm{C}$, mas de 28 para $37^{\circ} \mathrm{C}$ não houve alteração. Entretanto, quando a temperatura foi elevada para $47^{\circ} \mathrm{C}$ a porcentagem de descoloração inicial do corante diminuiu. A formação de peróxido de hidrogênio em água durante o tratamento por plasma diminuiu com o aumento da temperatura de 4 para $47^{\circ} \mathrm{C}$. A reação de descoloração ocorreu por um complexo mecanismo onde processos de zero e primeira ordem ocorreram numa mesma temperatura, seguindo ordem zero no início do processo e primeira ordem com o progresso da reação. A energia de ativação envolvida no processo de primeira ordem foi de $13,09 \mathrm{~kJ} \mathrm{~mol}^{-1}$.
\end{abstract}

This study investigates the effect of bath solution temperature on methylene blue decolorization in a point-to-plate electrical discharge plasma reactor. The results show an increase in the initial percentage of dye decolorization with an increase in the bath solution temperature from 4 to $28^{\circ} \mathrm{C}$, but from 28 to $37{ }^{\circ} \mathrm{C}$ there was no change. However, when the temperature was raised to $47{ }^{\circ} \mathrm{C}$ the initial dye decolorization percentage decreased. The hydrogen peroxide $\left(\mathrm{H}_{2} \mathrm{O}_{2}\right)$ formation in water during the plasma treatment decreased as the bath temperature increased from 4 to $47^{\circ} \mathrm{C}$. The dye decolorization reaction occurred via a complex mechanism where zero- and first-order processes took place at the same temperature, following zero-order in the initial step and first-order with the progress of the reaction. The activation energy involved in the first-order process was $13.09 \mathrm{~kJ} \mathrm{~mol}^{-1}$.

Keywords: methylene blue, decolorization, temperature effect, electrical discharge plasma

\section{Introduction}

The increase in the need for clean water worldwide has motivated the development of new technologies for water cleaning. Non-thermal plasma (NTP) is one of these emergent technologies and it can be efficiently applied to a large variety of environmental and industrial processes, in both the aqueous and gaseous phase, and it can be considered as a green technology, that is, less harmful to ecosystems than conventional technologies. ${ }^{1-3}$

Electrical discharges above or below the water surface have been shown to lead chemical activation of a system through the production of various reactive chemical species (e.g., $\mathrm{OH}, \mathrm{H}, \mathrm{O}, \mathrm{H}_{2} \mathrm{O}_{2}, \mathrm{H}_{2}, \mathrm{O}_{2}, \mathrm{O}_{3}$ ) that can be used to break

*e-mail: luskywalcker@yahoo.com.br, debacher@qmc.ufsc.br down and remove toxic organic contaminants (e.g., dyes, phenols, aromatic amines) present in the aqueous phase. ${ }^{1}$ The amount and nature of these oxidant species produced in water are dependent on the amount of energy added to the system and the gaseous atmosphere inducing the discharge (e.g., Ar, $\mathrm{O}_{2}, \mathrm{~N}_{2}$, air), as well as the $\mathrm{pH}$, conductivity and temperature of the aqueous phase.

Several types of plasma reactors, such as gas, liquid, or hybrid gas-liquid phase discharges, as well as different reactor and electrode geometries, have been proposed in the literature for organic compound degradation. ${ }^{1}$ The presence of water vapor, or a spray, in contact with the discharge plasma has been shown to increase the efficiency of the electrical discharge treatment. ${ }^{4}$ Different species are formed when the plasma source is placed in contact with liquids, and particular interest has been focused on the 
analysis of hydroxyl radicals $(\mathrm{OH})$ and hydrogen peroxide $\left(\mathrm{H}_{2} \mathrm{O}_{2}\right)$ generated in solution, since they have high oxidation potential (2.85 and $1.78 \mathrm{~V}$, respectively) thus being able to degrade a large number of organic pollutants. Moreover, the major processes which occur during the plasma treatment of organic pollutants involve secondary species $\left(\right.$ e.g. $\mathrm{H}_{2} \mathrm{O}_{2}$, $\mathrm{HNO}_{2}, \mathrm{HNO}_{3}, \mathrm{HOONO}$, ions). These result from reactions involving primary species (e.g., $\mathrm{H}, \mathrm{OH}, \mathrm{N}, \mathrm{O})$ generated directly by the discharge or combined with molecules of the feed gas, ${ }^{4}$ and their experimental control is of particular interest in terms of enhanced pollutant removal. The $\mathrm{H}_{2} \mathrm{O}_{2}$ generation in gas-liquid plasma reactors is dependent on different parameters, such as the gas composition $\left(\mathrm{O}_{2}, \mathrm{~N}_{2}\right.$, Ar etc), ${ }^{5}$ gas flow, electrical power applied and electrode shape. ${ }^{5}$ However, the rate and efficiency of $\mathrm{H}_{2} \mathrm{O}_{2}$ formation is not necessarily dependent on the electrode material. ${ }^{6}$

Another efficient strategy which can be applied to enhance the generation of active species and the consequent pollutant degradation is the combination of non-thermal plasma reactors with different advanced oxidation processes, such as ozonation, ${ }^{7} \mathrm{TiO}_{2}$ photo-catalysis, ${ }^{8-10}$ alumina and silica gel (resulting in adsorption) ${ }^{11}$ and homogeneous (e.g., $\mathrm{Fe}^{2+}$, resulting in the Fenton reaction), ${ }^{12}$ and heterogeneous (e.g., $\mathrm{Fe}_{3} \mathrm{O}_{4}$ and activated carbon) catalysts. ${ }^{13,14}$ In addition, hydrogen $\left(\mathrm{H}_{2}\right)$ generation from water in hybrid gas-liquid systems has also been reported as a clean energy source of fuel ${ }^{15-17}$ as well as the inactivation of micro-organisms by discharge plasma for water treatment, ${ }^{18}$ are among other NTP applications.

Several papers have reported studies on the $\mathrm{H}_{2} \mathrm{O}_{2}$ formation and organic dye degradation in electrical discharge plasma systems under different conditions. However, there is a lack of information concerning the effect of solution temperature on reactions involving electrical discharges. This is especially important, since to efficiently apply in situ electrical discharge reactors to wastewater treatment the influence of the bath solution temperature must be considered because wastewater temperatures may vary given the wide range of climates around the world, that is, the cold conditions of winter or near icy waters and the hotter ones found in summer or in tropical zones. The well known effect of temperature on the classical liquid-phase chemical reactions also applies to the analysis of electrical discharge processes inducing the degradation of organic molecules in the aqueous phase.

The main goal of this study is to investigate the effect of bath solution temperature on methylene blue (MB) (20.0 mg L $\mathrm{m}^{-1}$ ) decolorization and $\mathrm{H}_{2} \mathrm{O}_{2}$ formation in a point-to-plate electrical discharge plasma reactor. Also, the activation energy involved in the dye decolorization is estimated in order to better understand the chemical processes occurring in the liquid phase triggered by the electrical discharge.

\section{Experimental}

\section{Reagents}

All reagents were of analytical grade. $\mathrm{MB}$ $\left(\mathrm{C}_{16} \mathrm{H}_{18} \mathrm{~N}_{3} \mathrm{SCl} \cdot 3 \mathrm{H}_{2} \mathrm{O}\right)$, hydrogen peroxide $\left(\mathrm{H}_{2} \mathrm{O}_{2}\right)$, and ammonium vanadate $\left(\mathrm{NH}_{4} \mathrm{VO}_{3}\right)$ were purchased from Nuclear (Brazil), Vetec (Brazil), and Merck (Germany), respectively, and were used as received. Nitrogen gas $\left(\mathrm{N}_{2}\right)$ was purchased from White Martins Gases Industriais Ltda (Brazil) and deionized water was used in all solutions prepared.

\section{Apparatus}

The experimental apparatus shown in Figure 1 was used in this study at atmospheric pressure.

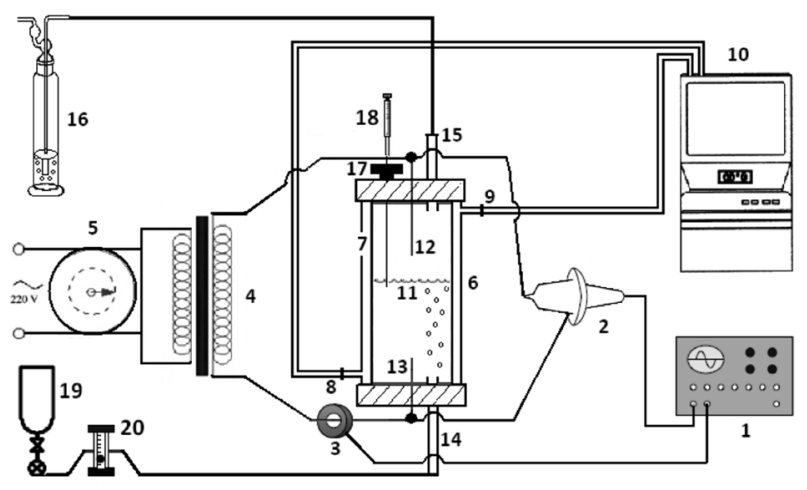

Figure 1. The experimental setup: (1) oscilloscope; (2) high voltage probe; (3) current probe; (4) AC high voltage neon transformer; (5) primary slide voltage; (6) electrical discharge plasma reactor; (7) water jacket; (8) input water cooler; (9) output water cooler; (10) thermostatized water/ ethylene glycol bath; (11) solution surface; (12) high voltage electrode; (13) electrical contact point; (14) input gas; (15) output gas; (16) gaswashing bottle; (17) screw cap with Teflon septum; (18) sampling syringe; (19) gas cylinder; (20) flow meter.

An AC high voltage neon transformer $(60 \mathrm{~Hz}$; $220 \mathrm{~V} / 17 \mathrm{kV}$; Neonena, Brazil) was used to generate the plasma channels between the single upper electrode and the water surface. The electrode had a diameter of $2.4 \mathrm{~mm}$ and was constructed in $2 \%$ thoriated tungsten with a conical end, and it was concentrically positioned in the reactor. Tungsten was chosen as the material due to its high erosion resistance. The discharge gap between the water surface and the upper electrode was fixed at $10 \mathrm{~mm}$. The electrical contact point protruded $10 \mathrm{~mm}$ from the bottom.

Nitrogen $\left(0.1 \mathrm{~L} \mathrm{~min}^{-1}\right)$ was used as the plasma gas and it was injected into the reactor through the input gas zone 
at the reactor bottom and the bubbles formed maintained the dye solution homogenized. In this way, the $\mathrm{N}_{2}$ feed gas produces a humid gas atmosphere where the discharge plasma is generated. The cylindrical glass reactor was made of borosilicate glass with an outer water jacket used to control the bath temperature during the experiments. The total reactor chamber volume was $200 \mathrm{~mL}$ and the experiments were performed using $100 \mathrm{~mL}$ of water/MB solution.

The current and voltage measurements were taken using a high voltage probe (Tektronix P6015A) and a current probe (Agilent N2781A) connected to an oscilloscope (Tektronix TDS5034B). Figure 2 shows the typical AC waveforms of the voltage and current cycles of the electrical discharge plasma reactor.

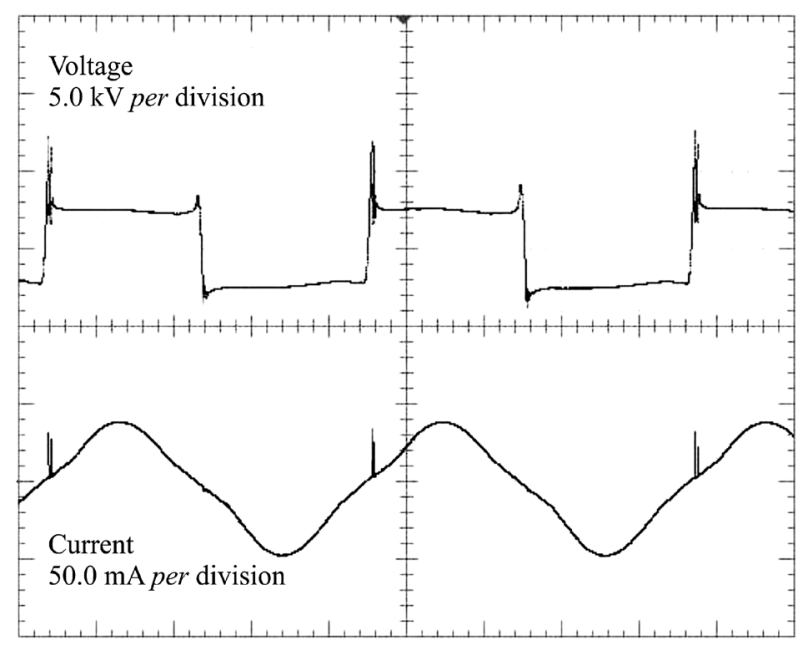

time / $4.0 \mathrm{~ms}$ per division

Figure 2. Typical AC waveforms of voltage and current of the electrical discharge plasma system used $\left(\mathrm{N}_{2}\right.$ gas flow $=0.1 \mathrm{~L} \mathrm{~min}^{-1}$; discharge gap $=10 \mathrm{~mm}$ ).

This reactor is also known as the dielectric barrier discharge (DBD) plasma reactor, where the deionized water used behaves as a dielectric barrier between the high voltage electrode and the electrical contact point. The electrical parameters applied to the reactor in all experiments were: $2.57 \mathrm{kV}, 27.7 \mathrm{~mA}$ and 59.2 W (RMS values). Although the amount of energy used in the DBD reactor is very low, it must be determined in order to predict the total cost of the process for future industrial applications.

\section{Procedure}

All experiments were performed at the initial $\mathrm{pH}$ (5.45) and conductivity $\left(1.4 \mu \mathrm{S} \mathrm{cm}^{-1}\right)$ of the deionized water (Figure 3). A volume of $95 \mathrm{~mL}$ of deionized water was added to the plasma reactor and left to reach the thermal equilibrium required for the experiments. The electrical discharge was then turned on for $15 \mathrm{~min}$ and $5 \mathrm{~mL}$ of $400.0 \mathrm{mg} \mathrm{L}^{-1} \mathrm{MB}\left(\mathrm{C}_{\mathrm{MB}}=20.0 \mathrm{mg} \mathrm{L}^{-1}\right)$ was added to the $95 \mathrm{~mL}$ of water remaining in the reactor chamber. The initial treatment time, $\mathrm{t}_{0}$, was considered to be the time of the addition of $5 \mathrm{~mL}$ of $\mathrm{MB} ; 1 \mathrm{~mL}$ aliquots were collected periodically from the plasma reactor during the treatment period (Figure 3). The amount of hydrogen peroxide $\left(\mathrm{H}_{2} \mathrm{O}_{2}\right)$ produced in the water by the plasma reactor was determined using $100 \mathrm{~mL}$ of deionized water and aliquots were collected periodically. All samples (MB and $\mathrm{H}_{2} \mathrm{O}_{2}$ ) were kept in a water bath at room temperature for a few minutes prior to the analysis to avoid undesired temperature effects (e.g., variations of $\varepsilon$ with temperature). The experimental values shown are the averages of three separate experiments at each temperature, except for the conductivity and $\mathrm{pH}$ measurements.

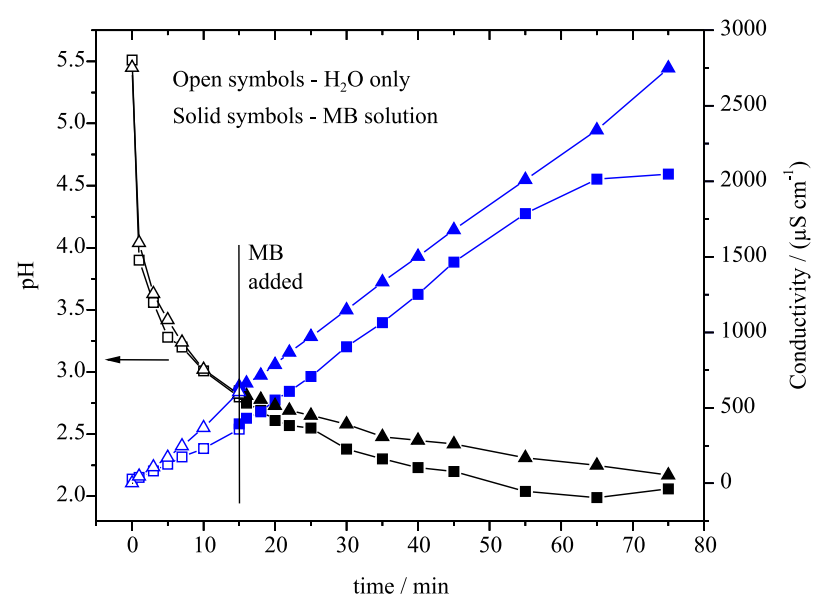

Figure 3. $\mathrm{pH}$ and conductivity profiles for the electrical discharge plasma treatment at $4{ }^{\circ} \mathrm{C}$ (squares) and $28^{\circ} \mathrm{C}$ (triangles). MB was added after $15 \mathrm{~min}$ of discharge application in deionized water.

\section{UV-Vis analysis}

The MB concentration was determined according to the Beer-Lambert law at the maximum absorbance $\left(\lambda_{\max }=664 \mathrm{~nm}\right)$ using a UV-Vis spectrophotometer (HP, model 8452A) with a spectral range of 190 to $820 \mathrm{~nm}$.

The decolorization percentage, $\mathrm{D} \%$, was determined using equation 1 :

$\mathrm{D} \%=\frac{\left(\mathrm{A}_{0}-\mathrm{A}_{\mathrm{t}}\right)}{\mathrm{A}_{0}} \times 100$

where $\mathrm{A}_{0}$ and $\mathrm{A}_{\mathrm{t}}$ stand for the absorbance at treatment time 0 and $t$, respectively.

The MB decolorization rate constants were obtained according to the zero- and first-order rate laws, which can be expressed by equations 2 and 3, respectively, as follows: 
$\mathrm{C}_{\mathrm{t}}=\mathrm{C}_{0}-\mathrm{k}_{0} \mathrm{t}$

$\ln \left(\mathrm{C}_{\mathrm{t}} / \mathrm{C}_{0}\right)=-\mathrm{k}_{1} \mathrm{t}$

where $\mathrm{C}_{\mathrm{t}}, \mathrm{C}_{0}, \mathrm{k}_{0}$ and $\mathrm{k}_{1}$, are the concentration of $\mathrm{MB}$ for a given reaction time, initial concentration, zero- $\left(\mathrm{mol} \mathrm{L}^{-1} \mathrm{~min}^{-1}\right)$ and first-order rate constant $\left(\mathrm{min}^{-1}\right)$, respectively.

In order to investigate the effect of solution temperature on $\mathrm{MB}\left(20 \mathrm{mg} \mathrm{L}^{-1}\right)$ decolorization in the absence of discharge plasma, two control experiments were carried out at 4 and $47^{\circ} \mathrm{C}$, under the same experimental conditions applied in the experiments with the discharge plasma on. No changes in absorbance values were observed in $60 \mathrm{~min}$ experiments at both temperatures, indicating that the MB did not thermally decompose under the experimental conditions used in this study in the absence of discharge.

The $\mathrm{H}_{2} \mathrm{O}_{2}$ concentration was determined using the vanadate method (equation 4) through comparison with appropriate calibration curves. ${ }^{19}$ The proposed method is based in the reaction between the vanadate ion and the hydrogen peroxide in acid medium leading to a red solution $\left(\lambda_{\max }=456 \mathrm{~nm}\right)$ due the formation of the peroxovanadium $(V)$ cation.

$\mathrm{VO}_{3}{ }^{-}+4 \mathrm{H}^{+}+\mathrm{H}_{2} \mathrm{O}_{2} \rightarrow \mathrm{VO}_{2}{ }^{3+}+3 \mathrm{H}_{2} \mathrm{O}$

\section{Bath solution temperature control}

All experiments were carried out with a controlled bath temperature regime in a thermostatized bath $(-20$ to $100 \pm 0.1^{\circ} \mathrm{C}$, Microquímica, MQBTC 99-20, Brazil), connected to the reactor by the outer water jacket. The solution was added to the reactor vessel and the bath temperature was adjusted. After the thermal equilibrium was reached the discharge was turned on.

\section{Activation energy determination}

The dependence of the MB decolorization rate on the temperature was studied at six different temperatures: 4, $11,20,28,37$, and $47{ }^{\circ} \mathrm{C}$. The first-order rate constants were estimated for every value and the Arrhenius equation in the linearized form, equation 5, was used to estimate the activation energy of the $\mathrm{MB}$ decolorization reaction in the electrical discharge plasma reactor:

$\ln \mathrm{k}_{1}=\ln \mathrm{A}-\frac{\mathrm{E}_{\mathrm{a}}}{\mathrm{RT}}$

where $\mathrm{E}_{\mathrm{a}}, \mathrm{A}, \mathrm{R}$ and $\mathrm{T}$ stand for the activation energy $\left(\mathrm{J} \mathrm{mol}^{-1}\right)$, frequency factor $\left(\mathrm{s}^{-1}\right)$, gas constant $\left(8.314 \mathrm{~J} \mathrm{~K}^{-1} \mathrm{~mol}^{-1}\right)$ and absolute temperature $(\mathrm{K})$, respectively.

\section{Statistical analysis}

The ANOVA and Student-Newman-Keuls (SNK) tests were used to compare the mean values at the 0.05 significance level. Greek letters in superscript were used to indicate that two or more means were not statistically different $(\mathrm{SNK}>0.05)$.

\section{Results and Discussion}

\section{Effect of temperature on the MB decolorization rate}

Figure 4 shows the effect of the solution temperature on the $\mathrm{MB}$ decolorization percentage against time.

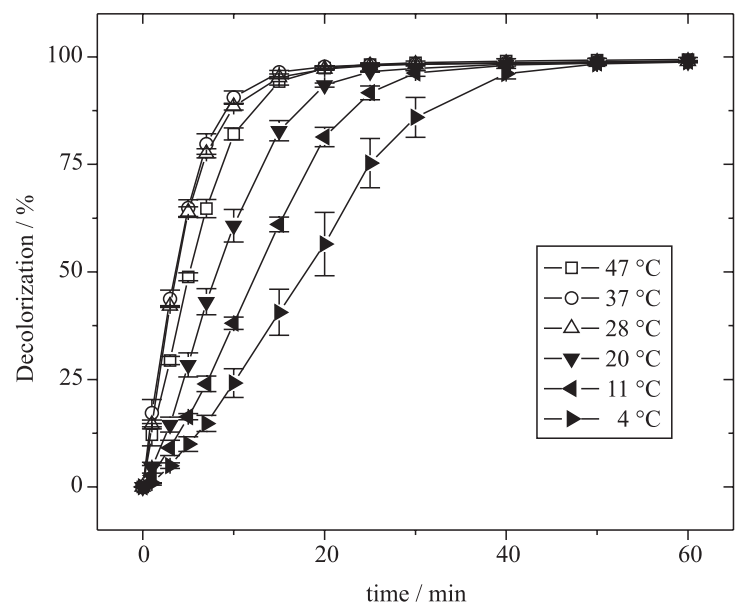

Figure 4. MB decolorization percentage at various temperatures, from 4 to $47^{\circ} \mathrm{C}$, in the electrical discharge plasma reactor (three replicates are shown for each experiment).

As shown in Figure 4, the initial decolorization percentage is enhanced on increasing the reactor solution temperature from 4 to $28{ }^{\circ} \mathrm{C}$ and from 28 to $37{ }^{\circ} \mathrm{C}$ the decolorization percentage remains almost constant. However, when the temperature was increased up to $47^{\circ} \mathrm{C}$ the initial decolorization percentage decreased, showing a negative effect of temperature.

Figure 5 exemplifies the zero- and the first-order kinetics regions used to calculate the $\mathrm{MB}$ decolorization rate constants according to equations 2 and 3. The MB decolorization reaction occurs via a complex mechanism where zero- and first-order processes takes place. At the same temperature, in concentrated MB solution, a zero-order rate law is observed and the decolorization process is a function of the plasma treatment time. When the dye solution becomes more diluted as a consequence of the discharge plasma, a first-order mechanism is observed and the process is governed by diffusion phenomena. ${ }^{4}$ 

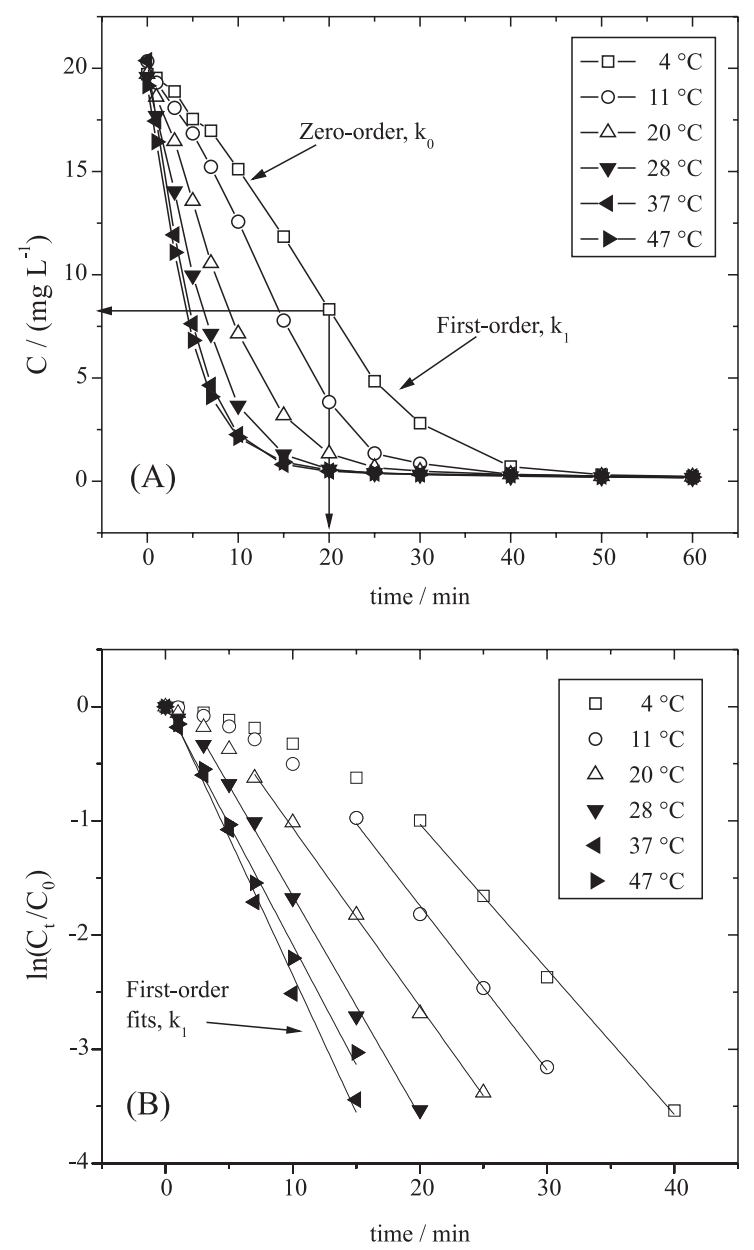

Figure 5. Zero- and first-order kinetics regions in direct scale (A) and logarithmic scale (B) according to the $790 \mathrm{~nm}$ UV-Vis band rising period for each temperature. To exemplify, only one of the three replicates is shown for each experiment.

As shown in Table 1, the zero-order rate constant $\left(\mathrm{k}_{0}\right)$ increased with the increase in the solution temperature from 4 to $37^{\circ} \mathrm{C}$. The same trend was observed for the first-order decolorization rate constant $\left(\mathrm{k}_{1}\right)$. However, on further increasing the solution temperature from 37 to $47^{\circ} \mathrm{C}, \mathrm{k}_{1}$ decreased to a value similar to that obtained at $28^{\circ} \mathrm{C}$ (Table 1 , SNK > 0.05).
The UV-Vis spectra (Figure 6) showed that MB absorption bands at $\lambda=292$ and $\lambda=664 \mathrm{~nm}$ were attenuated during the plasma treatment. However, a new absorption band was formed at $\lambda=790 \mathrm{~nm}$ and the time required for this band to reach the maximum absorbance was dependent on the solution temperature (Figure 6).

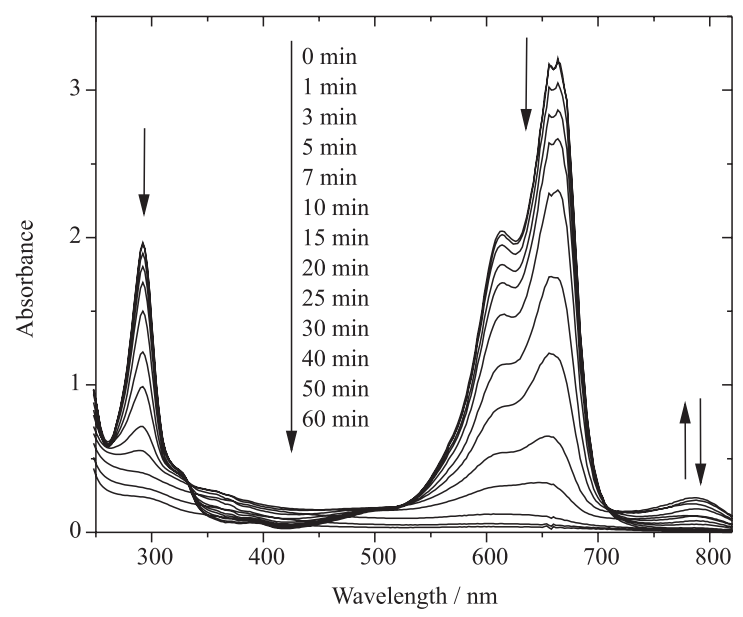

Figure 6. Temporal UV-Vis absorption spectra showing changes in MB concentration in aqueous solution during the plasma treatment at $11^{\circ} \mathrm{C}$.

The reaction order of the MB decolorization kinetics changed after this new band reached its maximum absorbance, as shown by the fits in Figure 5. The time required to reach the maximum absorbance value at $\lambda=790 \mathrm{~nm}$ (Figure 6) will be referred to herein as the 'rising period' and is shown in Table 2. The rising period may be related to the time required for an intermediate compound absorbing at $\lambda=790 \mathrm{~nm}$ to reach its maximum concentration (zero-order mechanism) and after that the MB decolorization mechanism changes (first-order mechanism). After the maximum absorbance had been reached, this band was also attenuated, which indicates that the intermediate compounds absorbing at $790 \mathrm{~nm}$ were degraded. The rate constants shown in Table 1 were calculated considering the rising period in which a zeroorder rate constant was adjusted within this time interval

Table 1. MB decolorization rate constants at different solution temperatures

\begin{tabular}{lcccc}
\hline $\mathrm{T} /{ }^{\circ} \mathrm{C}$ & $\mathrm{k}_{0} /\left(10^{-6} \mathrm{~mol} \mathrm{~L}^{-1} \mathrm{~min}^{-1}\right)$ & $*_{\mathrm{r}}^{2}$ & $\mathrm{k}_{1} / \mathrm{min}^{-1}$ & $* \mathrm{r}^{2}$ \\
\hline 4 & $1.512 \pm 0.238$ & $0.9889 \pm 0.00367$ & $0.1166 \pm 0.0093$ & $0.9948 \pm 0.00361$ \\
11 & $2.176 \pm 0.097$ & $0.9901 \pm 0.00157$ & $0.1495^{\alpha} \pm 0.0050$ & $0.9744 \pm 0.01968$ \\
20 & $3.204 \pm 0.251$ & $0.9865 \pm 0.00489$ & $0.1613^{\alpha} \pm 0.0045$ & $0.9918 \pm 0.01112$ \\
28 & $4.961 \pm 0.171$ & $0.9925 \pm 0.00843$ & $0.2047^{\beta} \pm 0.0117$ & $0.9935 \pm 0.00553$ \\
37 & $7.693 \pm 0.228$ & $0.9850 \pm 0.02291$ & $0.2295 \pm 0.0096$ & $0.9958 \pm 0.0026$ \\
47 & $6.540 \pm 0.223$ & $0.9597 \pm 0.05832$ & $0.2100^{\beta} \pm 0.0061$ & $0.9916 \pm 0.00752$ \\
\hline
\end{tabular}

The results are presented as mean \pm standard deviation of three replicate experiments at each temperature. *Correlation coefficient of straight lines. ANOVA test for $\mathrm{k}_{0}$ : $(\mathrm{F}=421.071 ; \mathrm{p}=0.000000)$. ANOVA test for $\mathrm{k}_{1}:(\mathrm{F}=83.512 ; \mathrm{p}=0.00000)$. Tests $\alpha / \alpha$ and $\beta / \beta$ : the mean values are not significantly different according to the SNK test $(\mathrm{p}>0.05)$. 
(Figure 5A) and first-order rate constants were calculated thereafter (Figure 5B). It should be noted that only 4, 3, and 4 points were used to estimate the zero-order rate constant fits at 28,37 , and $47{ }^{\circ} \mathrm{C}$, respectively (Figure 5, Table 2), and thus, these constants provide only a rough indication and may merely express some trend.

Table 2. The observed period in which the UV-Vis band at $790 \mathrm{~nm}$ achieves its maximum value ('rising period') at different solution temperatures

\begin{tabular}{cc}
\hline Solution Temperature $/{ }^{\circ} \mathrm{C}$ & Rising period $(\lambda=790 \mathrm{~nm}) / \mathrm{min}$ \\
\hline 4 & $0-20$ \\
11 & $0-15$ \\
20 & $0-7$ \\
28 & $0-5$ \\
37 & $0-3$ \\
47 & $0-5$ \\
\hline
\end{tabular}

The MB decolorization via $\mathrm{OH}$ radical addition in the $\mathrm{MB}$ rings has been previously reported by Oliveira et al. ${ }^{20}$ to occur in $\mathrm{H}_{2} \mathrm{O}_{2}-\mathrm{Nb} / \mathrm{Fe}$ oxidation catalysis via a heterogeneous Fenton mechanism in aqueous medium. Using positive ion mode electron spray ionization mass spectrometry (ESI-MS), the authors observed $\mathrm{m} / \mathrm{z}$ signals that are likely related to intermediates of MB oxidation, suggesting that the structural ring was broken down as a consequence of successive hydroxylation reactions. Interestingly, a temporal evolution of the $790 \mathrm{~nm}$ band can also be observed in the study by Oliveira et al. ${ }^{20}$ but no assignment or comments were provided. An induction period was reported suggesting that some degradation intermediates play an important role in promoting the Fenton reaction. Thus, the likely presence of similar hydroxylated MB intermediates may account for the rising period of the UV-Vis band at $790 \mathrm{~nm}$ in our study, during the electrical discharge plasma treatment.

It should be noted that zero-order reactions were also observed as a first kinetic step for concentrated solutions in gliding discharge reactors. ${ }^{4}$ In such systems, the electrodes are positioned in the gas phase above the liquid surface and the active species produced in the discharge plasma are carried by the flux gas and bombard the target molecules at the gas-liquid interface so that the organic molecule concentration is a linear function of the exposure time to the discharge. On the other hand, when the target solution becomes more diluted a first-order reaction is observed and the process is governed by diffusion phenomena.

In our study, when MB molecules are added in the reactor chamber (15 min of discharge), the liquid medium has already been modified by the presence of active species previously generated by the discharge plasma. Thus, these species react with the added MB molecules resulting in a wider time range in which the zero-order kinetics fit at low solution temperatures compared with in higher solution temperatures where the dye decolorization essentially follows a first-order mechanism. The hypotheses is that the reaction which leads to the formation of intermediates is dependent on the bath solution temperature and thus at low temperatures and more concentrated dye solution the decolorization reaction is catalyzed by the discharge plasma (e.g., UV radiation bombardment) at the gas-liquid interface, and follows zero-order kinetics, being a function of the time of exposure to the discharge. However, when the temperature increases, the decolorization reaction is governed by diffusion phenomena in the whole concentration range. Thus, the role of the interfacial reactions in the dye decolorization process are as important as the bulk reactions, and all of the active species previously generated by the discharge plasma may be able to react resulting in a first-order mechanism. The decrease in the $790 \mathrm{~nm}$ band rising period when the solution temperature increased is indicative that the formation and destruction of hydroxylated intermediate compounds originating from MB molecules takes place faster at higher temperatures.

\section{Effect of temperature on the $\mathrm{H}_{2} \mathrm{O}_{2}$ formation}

Figure 7 shows the dependence of the $\mathrm{H}_{2} \mathrm{O}_{2}$ formation on temperature in the electrical discharge plasma reactor using deionized water.

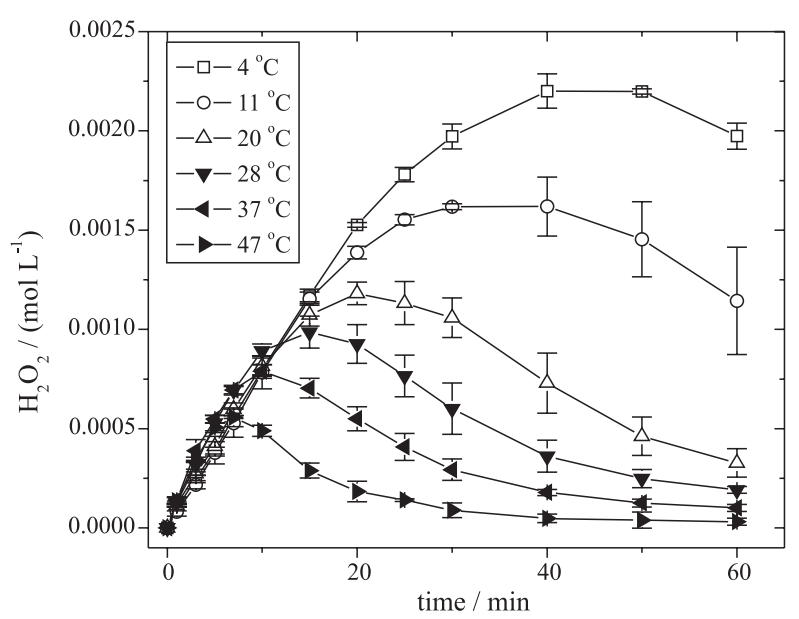

Figure 7. $\mathrm{H}_{2} \mathrm{O}_{2}$ formation according to solution temperature during electrical discharge plasma treatment (three replicates are shown for each experiment).

It can be seen that the maximum $\mathrm{H}_{2} \mathrm{O}_{2}$ formation during the plasma treatment decreased when the bath temperature was increased from 4 to $47^{\circ} \mathrm{C}$. Moreover, the time required to reach the maximum $\mathrm{H}_{2} \mathrm{O}_{2}$ concentration at 
each temperature decreased as the temperature increased. The maximum concentration, $2.2 \pm 0.013 \mathrm{mmol} \mathrm{L} \mathrm{m}^{-1}$, was observed at $4{ }^{\circ} \mathrm{C}$ after $40 \mathrm{~min}$, and for $47^{\circ} \mathrm{C}$ this value was $0.56 \pm 0.048 \mathrm{mmol} \mathrm{L}^{-1}$, after $7 \mathrm{~min}$ of discharge (Figure 7).

The general trend observed in Figure 7 is related to formation-destruction processes of $\mathrm{H}_{2} \mathrm{O}_{2}$ in the NTP system. The product formation process has a temperature independent rate which may be an indicative of plasma controlled reaction. On the other hand, the destruction process has a temperature dependent rate being dependent on the solution temperature adjusted.

It should be noted that at all temperatures studied, the $\mathrm{H}_{2} \mathrm{O}_{2}$ concentration decreased with the treatment time after its maximum value had been achieved. If the equilibrium reaction between formation and decomposition of $\mathrm{H}_{2} \mathrm{O}_{2}$ had been attained, an asymptotic-like behavior would be expected. However, the $\mathrm{H}_{2} \mathrm{O}_{2}$ concentration decreased, which may be related to side reactions involving $\mathrm{H}_{2} \mathrm{O}_{2}$ molecules and other species formed by means of the discharge plasma.

In order to assess the effect of conductivity, acidity, $\mathrm{NO}_{3}{ }^{-}$, and $\mathrm{NO}_{2}^{-}$species on the $\mathrm{H}_{2} \mathrm{O}_{2}$ concentration determined according to the vanadate method, six control experiments were carried out with no exposure to the discharge plasma at $47^{\circ} \mathrm{C}$ : five were performed by adjusting $100 \mathrm{~mL}$ of $\mathrm{H}_{2} \mathrm{O}_{2}$ aqueous solution $\left(7 \mathrm{mmol} \mathrm{L}^{-1}\right)$ to $1.4 \mu \mathrm{S} \mathrm{cm}^{-1}$ (deionized water); $1060 \mu \mathrm{S} \mathrm{cm}^{-1}$ ( $\mathrm{KCl}_{\text {addition); }}$ $2450 \mu \mathrm{S} \mathrm{cm}^{-1}$ ( $\mathrm{KCl}$ addition); $\mathrm{pH} 2$ ( $\mathrm{HCl}$ addition); and $\mathrm{pH} 2$ ( $\mathrm{HNO}_{3}$ addition); and one in the presence of $0.01 \mathrm{~mol} \mathrm{~L}^{-1}$ $\mathrm{NaNO}_{2}$. The $\mathrm{H}_{2} \mathrm{O}_{2}$ concentration was then monitored for 60 min. No changes in $\mathrm{H}_{2} \mathrm{O}_{2}$ concentration were observed in these experiments, except in the case where $\mathrm{NaNO}_{2}$ solution was added, where no $\mathrm{H}_{2} \mathrm{O}_{2}$ could be detected, even at zero minutes of experiment. This suggests that the reaction between $\mathrm{NO}_{2}{ }^{-}$and $\mathrm{H}_{2} \mathrm{O}_{2}$ took place immediately after $\mathrm{NO}_{2}{ }^{-}$addition to form peroxonitrous acid $(\mathrm{ONOOH})$, also reported by Moussa et al., ${ }^{21}$ who suggested that nitrous and peroxonitrous acids are the main oxidizing species involved in the temporal post discharge oxidation of methyl orange dye by gliding arc discharge. The proposed $\mathrm{ONOOH}$ formation reaction can be described by equation 6 .

$\mathrm{H}^{+}+\mathrm{NO}_{2}^{-}+\mathrm{H}_{2} \mathrm{O}_{2} \rightarrow \mathrm{ONOOH}+\mathrm{H}_{2} \mathrm{O}$

This reaction is immediately followed by a fast $\mathrm{ONOOH}$ isomerization reaction to produce $\mathrm{NO}_{3}{ }^{-}$in solution. ${ }^{21}$ Therefore, the $\mathrm{NO}_{2}{ }^{-}$anion formation in the plasma reactor and the reaction with $\mathrm{H}_{2} \mathrm{O}_{2}$ molecules to form peroxonitrous acid in the system may explain the observed decrease in $\mathrm{H}_{2} \mathrm{O}_{2}$ concentration with the treatment time after the maximum concentration had been achieved (Figure 7).
However, the effect of the bath solution temperature on the $\mathrm{NO}_{2}{ }^{-}$produced by the discharge is not clear, and further experiments need to be carried out to better understand this issue.

\section{General comments}

The first step in the MB decolorization is the formation of the chemically active species by means of the electrical discharge plasma. The discharge promotes a local heating in the water surface in contact with the plasma, promoting the transfer of water molecules from the liquid to the vapour phase. ${ }^{15,22}$ High energy electrons present in the discharge plasma are able to break down the water vapour molecules producing $\mathrm{OH}$ radicals in the gas phase $\mathrm{e}^{22}$ and also at the plasma-water interface. ${ }^{15}$ In addition, UV light generated by the discharge plasma also enhances the water and $\mathrm{H}_{2} \mathrm{O}_{2}$ dissociation reaction in the gas phase and at the gas-liquid interface and increase the formation of $\mathrm{OH}$ radicals. ${ }^{15,16}$ Besides no control experiments were perform in this work in order to estimate the effects of UV radiation, it is well established that discharges in and in contact with liquids generate intense UV radiation. ${ }^{15,16}$ The effect of UV radiation contribute to the decomposition of water vapor at gas phase leading to $\mathrm{OH}$ radicals production and promoting hydrogen generation in plasma chemical reactions. It was also observed that UV light generated in the gas phase above the water surface can penetrate into the water, leading to $\mathrm{OH}$ radicals production directly at the gas/liquid interface. ${ }^{15}$ Equations 8 and 11 presents some examples of photo-chemical reactions which may be taking place in the process, since $\mathrm{N}_{2}$ feeding gas produces strong light emission in the visible and UV spectral regions.

The species formed in the gas phase can subsequently be transferred from the gas to the liquid phase via complex mechanisms such as the electrohydrodynamic flow phenomena (the so called "corona wind") which enhance the transport at the gas-liquid interface, and thus different reactions take place in the liquid medium. ${ }^{23}$ Equations 7 to 13 summarize the active species production and the MB decolorization in the plasma reactor described above. Equations 12 and 13 are based on results obtained for the catalytic oxidation of $\mathrm{MB}$ dye. ${ }^{20}$ The successive hydroxylation in the MB molecules results in the ring opening, producing amines and organic acids in solution, which can ultimately lead to complete mineralization.

$$
\begin{aligned}
& \mathrm{H}_{2} \mathrm{O}+\mathrm{e}^{-} \rightarrow \mathrm{H}+\mathrm{OH}+\mathrm{e}^{-} \\
& \mathrm{H}_{2} \mathrm{O}+h v \rightarrow \mathrm{H}+\mathrm{OH} \\
& \mathrm{OH}+\mathrm{OH} \rightarrow \mathrm{H}_{2} \mathrm{O}_{2} \\
& \mathrm{H}+\mathrm{H} \rightarrow \mathrm{H}_{2}
\end{aligned}
$$




$$
\begin{aligned}
& \mathrm{H}_{2} \mathrm{O}_{2}+h v \rightarrow \mathrm{OH}+\mathrm{OH} \\
& \mathrm{OH}+\mathrm{MB} \rightarrow \mathrm{MB}-\mathrm{OH}+\mathrm{OH} \rightarrow \mathrm{MB}-(\mathrm{OH})_{2}+\mathrm{OH} \\
& \rightarrow \mathrm{MB}-(\mathrm{OH})_{3} \\
& \mathrm{MB}-(\mathrm{OH})_{3} \rightarrow \text { amines, organic acids, etc } \rightarrow \ldots \\
& \rightarrow \mathrm{CO}_{2}+\mathrm{H}_{2} \mathrm{O}
\end{aligned}
$$

Here, we have assumed that $\mathrm{OH}$ radicals $(2.85 \mathrm{~V})$ and $\mathrm{H}_{2} \mathrm{O}_{2}(1.68 \mathrm{~V})$ oxidants play major roles in the MB decolorization process. However, it should be noted that given the variety of oxidant species that may be formed directly or indirectly by the discharge plasma, other species may also contribute to the process. These include the previously mentioned peroxonitrous acid $(2.05 \mathrm{~V}), \mathrm{NO}_{2}$ $(1.05 \mathrm{~V}), \mathrm{HO}_{2}(1.70 \mathrm{~V})$ and possibly, to a small extent, different chlorine species formed from the $\mathrm{Cl}^{-}$anion present as the counter ion of the MB molecules in the analytical reagent which occurrence is only consider to a significant extent at about $\mathrm{pH} 2$ or below.

As shown in Figure 3, the ionic production in the electrical discharge plasma reactor is dependent on the temperature. It can be observed that both the $\mathrm{pH}$ and conductivity changed considerably during the treatment time at $4{ }^{\circ} \mathrm{C}$ and $28^{\circ} \mathrm{C}$. In the first $15 \mathrm{~min}$ of discharge only deionized water $\left(\mathrm{pH}_{0}=5.45 ; \kappa_{0}=1.4 \mu \mathrm{S} \mathrm{cm}^{-1}\right)$ was present in the reactor, resulting in an accentuated decrease in the $\mathrm{pH}$ value accompanied by an increase in the conductivity. Changes in the $\mathrm{pH}$ and conductivity are due to the formation of $\mathrm{H}_{3} \mathrm{O}^{+}$ions from the direct electron impact ionization of water as shown by equations 14 and $15.5,24$

$$
\begin{aligned}
& \mathrm{H}_{2} \mathrm{O}+\mathrm{e}^{-} \rightarrow \mathrm{H}_{2} \mathrm{O}^{+}+2 \mathrm{e}^{-} \\
& \mathrm{H}_{2} \mathrm{O}+\mathrm{H}_{2} \mathrm{O}^{+} \rightarrow \mathrm{OH}+\mathrm{H}_{3} \mathrm{O}^{+}
\end{aligned}
$$

In addition, using $\mathrm{N}_{2}$ as the feed gas in the electrical discharge plasma reactor, another effective acid source is attributed to the dissociation of nitrogen and oxygen (dissolved $\mathrm{O}_{2}$ and/or $\mathrm{O}$ radicals formed by direct electron impact with water) into $\mathrm{N}$ and $\mathrm{O}$ radicals. This is followed by recombination into nitrogen dioxide $\left(\mathrm{NO}_{2}\right)$ which dissolves in water and is transformed into $\mathrm{HNO}_{2}$ and $\mathrm{HNO}_{3}$ species which alter the $\mathrm{pH}$ and conductivity of the solution as shown by the following equations. . $^{54,25}$

$$
\begin{aligned}
& \mathrm{N}_{2}+\mathrm{e}^{-} \rightarrow 2 \mathrm{~N}+\mathrm{e}^{-} \\
& \mathrm{O}_{2}+\mathrm{e}^{-} \rightarrow 2 \mathrm{O}+\mathrm{e}^{-} \\
& \mathrm{N}+\mathrm{O} \rightarrow \mathrm{NO} \\
& \mathrm{NO}+\mathrm{O} \rightarrow \mathrm{NO}_{2} \\
& 3 \mathrm{NO}_{2}+\mathrm{H}_{2} \mathrm{O} \rightarrow 2 \mathrm{H}^{+}+2 \mathrm{NO}_{3}^{-}+\mathrm{NO} \\
& 2 \mathrm{NO}_{2(\mathrm{~g})} \rightarrow \mathrm{N}_{2} \mathrm{O}_{4(\mathrm{~g})} \\
& \mathrm{N}_{2} \mathrm{O}_{4(\mathrm{~g})}+\mathrm{H}_{2} \mathrm{O}_{(\mathrm{l})} \rightarrow \mathrm{HNO}_{3(\mathrm{l})}+\mathrm{HNO}_{2(\mathrm{l})} \\
& \mathrm{NO}_{2(\mathrm{~g})}+\mathrm{NO}_{(\mathrm{g})} \rightarrow \mathrm{N}_{2} \mathrm{O}_{3(\mathrm{~g})}
\end{aligned}
$$

$$
\begin{aligned}
& \mathrm{N}_{2} \mathrm{O}_{3(\mathrm{~g})}+\mathrm{H}_{2} \mathrm{O}_{(\mathrm{l})} \rightarrow 2 \mathrm{HNO}_{2(\mathrm{l})} \\
& 3 \mathrm{HNO}_{2(1)} \rightarrow \mathrm{HNO}_{3(\mathrm{l})}+2 \mathrm{NO}_{(\mathrm{g})}+\mathrm{H}_{2} \mathrm{O}_{(\mathrm{l})}
\end{aligned}
$$

Equations 16 to 18 relate to the primary species generated by the discharge plasma. In the case of $\mathrm{N}_{2}$ as the feed gas, the source of oxygen for the production of nitrogen oxides (equations 18 and 19) must come from the electron impact of water molecules. ${ }^{5,15}$ The combination of NO and O species leads to nitrite formation (equation 19) which subsequently gives rise to the production of nitrogen oxides in the liquid phase. The $\mathrm{NO}_{2}^{-}$and $\mathrm{NO}_{3}{ }^{-}$species appear as the ions matching the protons generated by the chemical reactions in the liquid phase during the plasma treatment.

After 15 min of discharge, MB was added to the reactor chamber and similar $\mathrm{pH}$ and conductivity changes were observed (Figure 3). Thus, the $\mathrm{H}_{3} \mathrm{O}^{+}$ion seems to be the dominant conductivity source even in the presence of MB molecules. An additional but lesser ion source may be the breakdown of MB molecules after successive hydroxylations ${ }^{20}$ which produces organic acids in solution and may contribute to the conductivity observed at higher temperatures where MB decolorization is enhanced.

Hydrogen peroxide plays an important role in advanced oxidation processes and many papers have shown that $\mathrm{H}_{2} \mathrm{O}_{2}$ originating from $\mathrm{OH}$ radicals produced by electrical discharges could be involved in organic molecule breakdown in the aqueous phase, since $\mathrm{H}_{2} \mathrm{O}_{2}$ is a strong oxidant. ${ }^{21,26} \mathrm{Du}$ et al.,${ }^{27} \mathrm{using}$ a gas-liquid gliding arc reactor, reported that the higher $\mathrm{H}_{2} \mathrm{O}_{2}$ concentration was partly responsible for the higher degradation rate and degradation kinetics constant observed for the dye acid orange 7 when the feed gas was oxygen in comparison with air, nitrogen or argon at the same temperature.

In our study, the highest $\mathrm{H}_{2} \mathrm{O}_{2}$ concentration produced at $4{ }^{\circ} \mathrm{C}$ using $\mathrm{N}_{2}$ as the feed gas (Figure 7) did not result in the highest dye decolorization rates (Table 1). This may be explained by the diffusion effect of dye and $\mathrm{H}_{2} \mathrm{O}_{2}$ molecules in the liquid phase due to the viscosity of water, since both parameters are temperature-dependent, assuming that the $\mathrm{H}_{2} \mathrm{O}_{2}$ formation in the presence of $\mathrm{MB}$ molecules follows the same behavior observed using pure deionized water only. The viscosity of water decreases from $1.567 \times 10^{-3} \mathrm{~N} \mathrm{~m}^{-2} \mathrm{~s}$ at $4{ }^{\circ} \mathrm{C}$ to $0.6915 \times 10^{-3} \mathrm{~N} \mathrm{~m}^{-2} \mathrm{~s}$ at $37{ }^{\circ} \mathrm{C},{ }^{28}$ resulting in an increase in the diffusion of the reactant molecules. As the solution temperature increases, the probability of effective collision between the $\mathrm{H}_{2} \mathrm{O}_{2}$ and dye molecules is favored, resulting in the highest rate constants being observed at $37^{\circ} \mathrm{C}$. When the solution temperature is over $37^{\circ} \mathrm{C}$, less $\mathrm{H}_{2} \mathrm{O}_{2}$ molecules are formed and also more species may be transferred from the liquid to the gas phase by vaporization and/or may be thermally 
decomposed to $\mathrm{H}_{2} \mathrm{O}$ and $\mathrm{O}_{2}$, resulting in the lower rate constant observed at $47^{\circ} \mathrm{C}$ in comparison to $37^{\circ} \mathrm{C}$ (Table 1, $\mathrm{SNK}<0.05)$. Thus, the temperature of $37^{\circ} \mathrm{C}$ presented the optimum temperature in terms of the parameters related to the MB decolorization by the electrical discharge plasma reactor in this study.

Finally, as pointed out by Locke $e t$ al.,$^{1}$ the reliability of the analysis of the electrical discharge process considered as a two-step process: the formation of reactive species by fast physical-chemical processes and the subsequent relatively slower chemical degradation reactions, remains uncertain. However, the effect of solution temperature on MB decolorization may be explained on the basis that the plasma induces the formation of reactive species above the water surface followed by classical chemical reactions in the aqueous phase.

\section{Activation energy results}

The MB decolorization follows a first-order rate law in more diluted dye solutions, equation 2, at all temperatures studied. The correlation between the rate constant $\mathrm{k}$ and temperature $\mathrm{T}$ (Table 1), the activation energy of a reaction, can be determined using the Arrhenius equation (equation 5). ${ }^{29}$

Figure 8 shows the plot of $\operatorname{lnk}_{1}\left(\mathrm{~s}^{-1}\right)$ against $1 / \mathrm{T}\left(\mathrm{K}^{-1}\right)$ in the temperature range of 4 to $37{ }^{\circ} \mathrm{C}$. As increases in temperature above $37{ }^{\circ} \mathrm{C}$ resulted in a negative effect of temperature on the $\mathrm{MB}$ decolorization, the $\ln \mathrm{k}_{1}$ value at $47^{\circ} \mathrm{C}$ was not used in the Arrhenius plot.

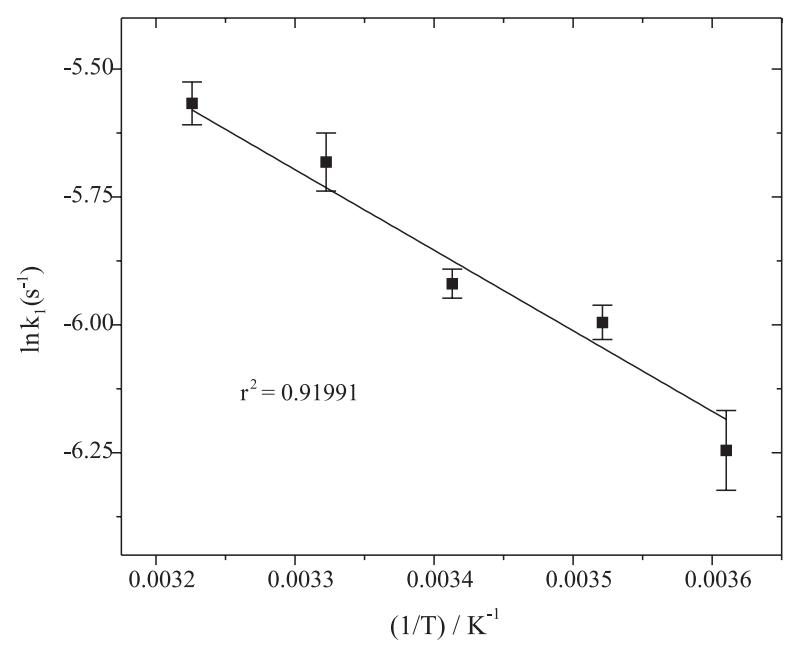

Figure 8. Arrhenius plot of rate constant against temperature for MB decolorization in the electrical discharge plasma reactor at temperatures ranging from $4{ }^{\circ} \mathrm{C}$ to $37^{\circ} \mathrm{C}$.

From the slope in Figure 8, the activation energy, $\mathrm{E}_{\mathrm{a}}$, obtained in the electrical discharge plasma reactor was $13.09 \mathrm{~kJ} \mathrm{~mol}^{-1}$. Higher $\left(60.7 \mathrm{~kJ} \mathrm{~mol}^{-1}\right)$ and similar $\left(14.45 \mathrm{~kJ} \mathrm{~mol}^{-1}\right)$ activation energy values can be found in the literature for the photocatalytic/ $\mathrm{TiO}_{2} \mathrm{MB}$ decolorization within different temperature ranges. ${ }^{30,31}$

As stated by Ling et al. ${ }^{32}$ the photocatalytic oxidation process does not require heating because it is initiated by photonic activation, and thus the activation energy may be close to zero. The authors concluded that the reported values ranging from 5 to $20 \mathrm{~kJ} \mathrm{~mol}^{-1}$ are very close to those of a hydroxyl radical reaction and suggested that organic compound decomposition through a photocatalytic reaction might be controlled by the hydroxyl radical reaction.

Since the activation energy of a physical process is lower than that of a chemical process such as a chemical reaction, ${ }^{33}$ the activation energy obtained in this study reflects the effect of temperature on the radical/MB decolorization reaction in solution, and might not compute physical processes (e.g., shock waves, light emission) derived from the high electric field.

We also performed the activation energy estimative for $\mathrm{H}_{2} \mathrm{O}_{2}$ destruction in the NTP reactor according to the experimental data shown in Figure 7. By fitting with birthand-death kinetics for an intermediate, ${ }^{34}$ the activation energy for $\mathrm{H}_{2} \mathrm{O}_{2}$ destruction in the NTP reactor according to the Arrhenius equation was determined to be $9.30 \mathrm{~kJ} \mathrm{~mol}^{-1}$ in the temperature range from 4 to $47^{\circ} \mathrm{C}$.

Finally, it should be noted that the activation energy obtained here may be reduced if the experimental conditions applied are changed, e.g. gas atmosphere and addition of homogeneous or heterogeneous catalyst.

\section{Conclusions}

To efficiently apply in situ non thermal plasma reactors to wastewater treatment, the bath solution temperature effects must be considered since wastewater temperatures may vary given the wide range of climates around the world.

To demonstrate this, MB decolorization in an electrical discharge plasma reactor was experimentally studied varying the bath solution temperature within the range of 4 to $47^{\circ} \mathrm{C}$. The initial dye decolorization percentage increased as the bath temperature increased except at $47^{\circ} \mathrm{C}$, for which a decrease in the MB decolorization was observed. The $\mathrm{H}_{2} \mathrm{O}_{2}$ formation increased as the bath temperature decreased and the maximum $\mathrm{H}_{2} \mathrm{O}_{2}$ concentration was observed at $4{ }^{\circ} \mathrm{C}$.

The effect of solution temperature on the $\mathrm{MB}$ decolorization in the electrical discharge plasma reactor may be controlled by the viscosity and diffusion coefficients of the water and dye $/ \mathrm{H}_{2} \mathrm{O}_{2}$ molecules. It was found that $37^{\circ} \mathrm{C}$ presented the optimum parameters related to the dye decolorization in this study. 
The activation energy involved in the MB decolorization reaction in the electrical discharge plasma reactor, determined according to the Arrhenius equation, was $13.09 \mathrm{~kJ} \mathrm{~mol}^{-1}$ within the temperature range of 4 to $37{ }^{\circ} \mathrm{C}$.

\section{Acknowledgments}

L. O. de B. Benetoli and B. M. Cadorin acknowledge doctoral and IC scholarships from CNPq and PIBIC/CNPq, respectively. We would like to express sincere thanks to Professor Arnaldo J. Perin (INEP-UFSC) for providing the electrical measurements. We also like to dedicate this work in memory of Professor Jen-Shih Chang (McMaster University), for all his help, teaching and wisdom.

\section{References}

1. Locke, B. R.; Sato, M.; Sunka, P.; Hoffmann, M. R.; Chang, J.-S.; Ind. Eng. Chem. Res. 2006, 45, 882.

2. Chang, J. -S.; Sci. Technol. Adv. Mater. 2001, 2, 571.

3. Chen, Y.-C; Lee, H. -M; Huang, M. -H; Chen, S. -H.; Proceedings of the $6^{\text {th }}$ International Symposium on NonThermal Plasma Technology, Wan-Li, Taipei, Taiwan, 2008.

4. Brisset, J-. L.; Moussa, D.; Doubla, A.; Hnatiuc, E.; Hnatiuc, B.; Youbi, G. K.; Herry, J-. M.; Naïtali, M.; Bellon-Fontaine, M-. N.; Ind. Eng. Chem. Res. 2008, 47, 5761.

5. Burlica, R.; Kirkpatrick, M. J.; Locke, B. R.; J. Electrostat. 2006, 64, 35.

6. Holzer, F.; Locke, B. R.; Plasma Chem. Plasma Process. 2008, 28,1 .

7. Malik, M. A.; Ubaid-ur-Rehman; Ghaffar, A.; Ahmed, K.; Plasma Sources Sci. Technol. 2002, 11, 236.

8. Wang, H.; Li, J.; Quan, X.; Wu, Y.; Appl. Catal., B 2008, 83, 72.

9. Lukes, P.; Clupek, M.; Babicky, V.; Janda, V.; Sunka, P.; J. Phys. D: Appl. Phys. 2005, 38, 409.

10. Hao, X. L.; Zhou, M. H.; Lei, L. C.; J. Hazard. Mater. 2007, 141,475 .

11. Malik, M. A.; Plasma Sources Sci. Technol. 2003, 12, S26.

12. Grymonpré, D. R.; Sharma, A. K.; Finney, W. C.; Locke. B. R.; Chem. Eng. J. 2001, 82, 189.

13. Lei, L.; Zhang, Y.; Zhang, X.; Shen, Y.; J. Electrostat. 2008, 66, 16.
14. Grymonpré, D. R.; Finney, W. C.; Clark, R. J.; Locke, B. R.; Ind. Eng. Chem. Res. 2003, 42, 5117.

15. Park, J. Y.; Kostyuk, P. V.; Han, S. B.; Kim, J. S.; Vu, C. N.; Lee, H. W.; J. Phys. D: Appl. Phys. 2006, 39, 3805.

16. Kostyuk, P. V.; Park, J. Y.; Han, S. B.; Park, H. S.; J. Phys. D: Appl. Phys. 2008, 41, 095202.

17. Burlica, R.; Shih, K. -Y.; Locke, B. R.; Ind. Eng. Chem. Res. 2010, 49, 6342.

18. Chen, C. -W.; Lee, H. -M.; Chang, M. -B.; J. Electrostat. 2009, 67, 703.

19. Nogueira, R. F. P.; Oliveira, M. C.; Paterlini, W. C.; Talanta 2005, 66, 86 .

20. Oliveira, L. C. A.; Gonçalves, M.; Guerreiro, M. C.; Ramalho, T. C.; Fabris, J. D.; Pereira, M. C.; Sapag, K.; Appl. Catal., A 2007, 316, 117.

21. Mousa, D.; Doubla, A.; Kamgang-Youbi, G.; Brisset, J. L.; IEEE Trans. Plasma Sci. 2007, 35, 444.

22. Lukes, P.; Locke, B. R.; J. Phys. D: Appl. Phys. 2005, 38, 4074.

23. Ohyama, R.; Inoue, K.; Chang, J. S.; J. Phys. D: Appl. Phys. 2007, 40, 573.

24. Burlica, R.; Locke, B. R.; IEEE Trans. Ind. Appl. 2008 44, 482.

25. Ryu, S.; Park, H.; J. Electrostat. 2009, 67, 723.

26. Kirkpatrick, M.; Locke, B. R.; Ind. Eng. Chem. Res. 2005, 44, 4243.

27. Du, C. M.; Shi, T. H.; Sun, Y. W.; Zhuang, X. F.; J. Hazard. Mater. 2008, 154, 1192.

28. Weast, R. C.; CRC Handbook of Chemistry and Physics, $60^{\text {th }}$ ed., CRC Press: Boca Raton, USA, 1979.

29. Avery, H. E.; Basic Reaction Kinetics and Mechanisms, Macmillan Education Ltd: London, 1974.

30. Naskar, S.; Pillay. S. A.; Chanda, M.; J. Photochem. Photobiol., A 1998, 113, 257.

31. Lee, B. -N.; Liaw, W. -D.; Lou, J. -C.; Environ. Eng. Sci. 1999, $16,165$.

32. Ling, C. M.; Mohamed, A. R.; Bhatia, S.; Chemosphere 2004, $57,547$.

33. Wu, C. H.; Chern, J. M.; Ind. Eng. Chem. Res. 2006, 45, 6450.

34. Moore, J. W.; Pearson, R. G.; Kinetics and Mechanism, $3^{\text {rd }}$ ed., John Wiley \& Sons: New York, 1981.

Submitted: December 13, 2010

Published online: June 9, 2011 